American literature, where since 1914 a great body of evidence has accumulated, and upon my experience of fractional test-meals during the past six months at St. Mary's Hospital.

The position is very fairly stated by Rehfuss and Hawk. ${ }^{1}$ No extravagant claims are advanced; the method is a useful, if modest, addition to our means of investigation, and we surely have need of every measure that can in any way contribute to accuracy in diagnosis. Moynihan writes :-

"More mistakes are made in the diagnosis of gastric ulcer than is the case in any other abdominal disorder. If all the methods of examination are strictly brought to bear upon cases commonly referred to as those of gastric ulcer, it will be found that in the majority the diagnosis cannot be upheld.'

This, apparently, is also the experience of the Mayo Clinic, for Smithies, in an article printed in June this year, states that only 53 per cent. of patients sent to hospital diagnosed as gastric ulcer turn out to be such.

The time, then, is not perhaps inopportune for advancing a plea that no stone should be left unturned in the quest for greater accuracy in gastro-intestinal diagnosis. The first fine careless rapture of our surgical brethren, inspized by the early and brilliant results of gastro-enterostomy, has passed. A more sober spirit is abroad. Many cases have been successfully relieved, others have now been followed from the time they leave the surgeon's hands, through a period of apparent cure, to the return, and often aggravation, of the old symptoms. There has arisen a feeling that more careful selection of cases for operation, based upon exhaustive investigations, must precede further advances, and that any measures which contribute to our knowledge of either motor or secretory abnormalities, with its implied knowledge of the limits of the normal must tend to avert a repetition of these failures. Dr. Ryle's article is a step towards that end.

Nevertheless, it is as well to continue our search for answers to ultimate questions in gastric and intestinal pathology along other lines. To quote the writer whose views open this letter:-

"An attempt to evolve a gastro-intestinal pathology fundamentally on the basis of secretory variations is to lean on a frail reed. ..... The curve is only one of the many clinical data which does not furnish the answer itself, but which adds its little to the many other aids at our command in reaching a true conception of the underlying disease process."

I am, Sir, yours faithfully,

South Audley-street, W., Sept. 6th, 1920. C. M. WILSON.

\section{THE PROBLEM OF DENTAL DISEASE.}

\section{To the Eaitor of THE LANCET.}

SIR, - I read with pleasure your annotation under this heading in THE LANCET of August 21st. In this connexion may be mentioned some clinical observations made by me at the Luxor hospital for natives in Uppex Egypt prior to 1914. Neither appendicitis nor gastric ulcer appeared among my cases, and cancer was rare. Though syphilis was widespread, yet I found no cases of aneurysm or of locomotor ataxy. As regards cancer, the absence of post-mortem examinations may vitiate my impressions of cancer incidence, but I never saw any kind of growth in a breast nor any cases of mammary abscess. My friend Dr. G. W. Ellacombe, of Livingstone, Northern Rhodesia, had similar expe rienees among his native patients.

I suggest that immunity from appendicitis and gastric ulcer depended on the nature of the diet, as a result of which, I claim, the population had good teeth. May the absence of gastro-intestinal cancer be due to this also? I would suggest to the Rockefeller Institute that the study of the diet and diseases of the country Arab as compared with his brother living in Cairo and Alexandria might be of value. Owing to the spread of four-mills and sweet-shops the diet is rapidly changing, but it is still possible to study the native eating coarse wholemeal unleavened bread, and no sugar beyond the natural solution which he extracts from the fibrous cane and from other fruits.

A short time ago Professor J. G. Adami was reported to have stated that the teeth of the U.S.A. citizen were far better than ours. With the utmost respect, I

\footnotetext{
1 Journal of the American Medical Association, Angust 14th, 1920.
}

venture to doubt his statement. It is my belief that the teeth of American citizens are extensively diseased, and the very number and importance of their dental surgeons would seem to support my statement. Now that the U.S.A. have gone "dry," and in consequence still more "sweet," the dental surgeons and doctors will doubtless be busier than ever. The suggestion that 10,000 more dental surgeons are required in this country is also attributed to Professor Adami. I protest at being asked to pay for this expensive host of officials when the advanced disease which they are to scrape out and plug can be almost entirely prevented by common-sense feeding and discipline in the home. Dr. Sim Wallace and others have actually proved that prevention is simple and inexpensive. Dr. James Wheatley, medical officer of health for Shropshire, also has figures pointing to the improvement of the children's teeth under war circumstances which are arresting and which I trust be will publish. For example, cow's milk is an entirely unnatural food for the human child, and its consumption in large quantities may have disastrous results to the children and sick people whose staple diet it has become. Just as alcohol in the form of wine, beer, or spirits does no harm, but in many cases positive good when taken in moderation, so it is with commercial sugar and with milk. There is far too much stress laid to-day upon heat calories and far too little upon the number and kind of meals necessary to exercise the teeth and keep the mouth clean and healthy. Much money and illness and many operations for gastric ulcer and appendicitis could be saved by putting the true facts about dental caries before the women of the country.

I am, Sir, yours faithfully,

W. E. NICKOLLS DUNN, M.B. Lond.

Brighton, August 30th, 1920.

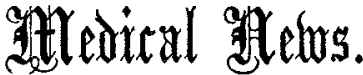

A JoINT Conference of the Central Association for the Care of the Mentally Defective and the National Special Schools Union will be held at the Church House, Westminster, from Thursday to Saturday, Nov. 25th-27th. The Right Hon. H. A. L. Fisher is expected to address the opening session, at which Mr. Leslie Scott will preside Sir William Byrne will be in the chair on the second day, and Dr. A. E. Eichholz on Saturday morning. Further information from the honorary secretary of the Central Association, Queen Anne's Chambers, Tothill-street, London, S.W. 1.

UNIVERSITY OF LONDON.-Preliminary arrangements for advanced lectures in physiology for the session 1920-21, details of which will be announced later, show a varied programme of courses to be delivered by distinguished physiologists :-

During the first term at King's College Dr. C. Da Fano will lecture on Histology of the Nervous System on Wednesdays, at 4.30 P.M. beginning on Oct. 13th.

At the University Buildings, South Kensington, Prof A. D. Walle in conjunction with $\mathrm{Mr}$. J. C. Waller) will give a course of eigh lectures on Experimental Studies in Vegetable Physiology and Vegetable Electricity on Tuesdays, beginning on Oct. 12th

During the second term Prof. M. S. Pembrey, at Guy's Hospital, will give eight lectures on the Physiology of the Emy Hospita will give eight lectures on the Physiology of the Embryo, Fetus and Newly Born, on Thursdays, at 4.30 , and Mr. J. A. Gardner give a course on Bio-Chemistry (title and place not yet arranged). In the third term a course of lectures by various lecturers, to be and Prof. H. E. Roaf will give eight lectures at the London Hospital on Reception of Sensory Stimuli. All these courses are recognised as advanced lectures which a
candidate for $\mathrm{B}$. Sc. honours may name for part of his examination. The following scheme of intercollegiate advanced work in physiology has been approved for the Honours B.Sc. Examination, and students of the participating colleges are free to attend all the courses :-

First term : Prof. W. M. Bayliss (University College), Physical Chemistry in Relation to Physiology.

Second term: Prof. W. D. Halliburton and Dr. Rosenheim (King's College), Advanced Chemical Physiology; and Prof. M. S. Pembrey (Guy's Hospital), Practical Work on Respiration.

Third term: Dr. J. S. Edkins (Bedford College), Advanced PracThird term: Dr. J. S. Edkins (Bedford College), Advanced Prac-
tical Histology; and Prof. F. A. Bainbridge (St. Bartholomew's tical Histology ; and Prof. F. A. Bainbridge (St. Bartholomew's Hospitall, course of
and Cardiac Muscle.

Students requiring further information regarding the lectures should address their inquiries to the heads of the laboratories at which they will be delivered. 